\title{
Analysis of the effects of the development of traditional tectonic systems of low-rise buildings
}

\author{
Alexander Pleshivtsev ${ }^{1 *}$, and Tatiana Pakunova ${ }^{1}$ \\ ${ }^{1}$ State University of land management , 105064, 15 Kazakova str., Moscow, Russia
}

\begin{abstract}
The Genesis of architectural science (in the framework of the development of the theory of architecture) is accompanied (clarified, supplemented, changed) by the conceptual and semantic meaning of tectonics - one of the main categories of composition (architectural composition). In the theory of architecture (as a special field of architectural science), the concept of "tectonics" is associated with various aspects of the architectural image: the expression of artistic and aesthetic concept; display of the interaction of the structural basis and form; the implementation of exclusively utilitarian features of the object, without taking into account the established laws and the place of tectonics in the composition, the Systemicity of the architectural environment is formed by the system of the human activity itself, focused on the analysis of the surrounding world (space). Architectural practice involves the formation of artificial systems, which are usually understood as organized material structures and related functional processes of life and production activity, which allow to implement certain efforts to achieve this goal. The architectural systems intended for a certain type of utilitarian and functional activity acquire the status of architectural (production, townplanning) object and are systematized according to certain typological signs and classification rules.
\end{abstract}

\section{Introduction}

This research is based on the scientific hypothesis about the systemic nature at influencing factors that determine the peculiarities state and genesis in traditional tectonic (architectural) systems. The subject of research is the most visible (main) types architectural systems in buildings and structures, characteristic of the various stages of: historical, technological and social development. The relevance this research is related to the assessment at the scale application at traditional tectonic systems and the assessment in promising possibilities for the development of the considered material objects in architectural activity.

\footnotetext{
* Corresponding author: perspektiva-aa@mail.ru
} 
In the most General case, the system (from the Greek "sistema" - "whole, composed of parts") refers to some commonality (integrity), organized on the basis of a certain principle, in which all the elements are so interdependent from one another, that act with respect to the environment and other systems, as a single and integral entity [1, 2].

Architectural activity involves the creation of such artificial (architectural) systems, which are usually understood as organized material structures, which are characterized by the following main features [3-5]:

- own functional purpose;

- a set of individual (unique) or common (typical) features;

- the original aesthetic value and cultural level of display;

- authentic author's vision of adaptation and interaction with the natural (naturallandscape) and artificial (architectural, urban) environment;

- method of interaction of internal spatial structure with external social and social factors.

The formation of the architectural image is carried out through the organization of the method of interaction of the constructive solution and the artistic and aesthetic representation of the corresponding architectural system. The choice of the design solution is determined by the tectonic features of the functioning of the structural elements included in the structural system, the properties of materials of structures, technological methods necessary for their manufacture and construction.

The aim of the work is to study the work of logistics systems during the operation of pipelines for various purposes to eliminate possible risks.

\section{Materials and methods}

Tectonics is a specific means of architectural expression, organically associated with the architectural (structural) system of an architectural object (building or structure) and the objective laws of its creation - strength, stability and balance, taking into account the strength properties of materials, the principles of transmission and perception of load combinations. In the theory of architecture (as a special field of architectural science) the concept of "tectonics" is associated with various aspects of the architectural image: the expression of artistic and aesthetic concept; by showing how structural foundations and forms [6-8].

The formation of architectural systems and tectonic mapping of the main features of their functioning and representation is based on the composition of the solutions of their spatial structure, which is formed in strict accordance with the rules and worldview of the relevant era, the level of development of the productive forces of society, as well as modern social and social conditions [9, 10].

Depending on the level of development of scientific knowledge, the state of technical and technological capabilities for manufacturing and practical implementation through appropriate construction techniques, architectural systems are classified into several main or traditional types (order, arch-vaulted, wall, frame-rack) [11-15].

Each of the main types of architectural systems is characterized by certain tectonic features, technical (technological) logic, capabilities and certain laws for architectural shaping. Architectural practice of various (past) historical epochs allowed to establish and develop elements as part of a certain type of traditional architectural system (form) [16-20].

One of the most important features that characterize the integrity of the composition is the harmonious unity of artistic and aesthetic expression and rational constructive system of architectural image. The solution of the question of artistic and aesthetic properties of the design is characterized by a special, specific complexity. Evaluation of the architectural 
object includes indicators of the quality of the design and artistic expression, which allow to identify the content, to reveal the meaning and idea of the architectural image.

Tectonics of the constructive solution (traditional tectonic system) is a special means of displaying the artistic idea of the author of the architectural image and directly depends on the accepted worldview of the historical era. Thus, tectonic representation is not only a source of inspiration and renewal of the concepts of architectural form, but also a reflection of the meaning of life of the era.

The Genesis of architectural science (in the framework of the development of the theory of architecture) is accompanied (clarified, supplemented, changed) by the conceptual and semantic meaning of tectonics - one of the main categories of composition (architectural composition).

In the theory of architecture (as a special field of architectural science), the concept of "tectonics" is associated with various aspects of the architectural image: the expression of artistic and aesthetic concept; display of the interaction of the structural basis and form; implementation of exclusively utilitarian features of the object, without taking into account the established laws and place of tectonics in the composition.

The term "architectonics" which appeared a little later only emphasizes the diverse semantic row enclosed in the conceptual device of one of the most "young" categories of composition.

To date, the theory of architecture have not developed precise and clearly perceive a scientific definition for the great majority of basic abstractions, including the concept under consideration: "tectonics" and "architectonics".

Tectonics is a specific means of architectural expression, organically associated with the architectural (structural) system of the building and the objective laws of its creation strength, stability and balance, taking into account the strength properties of materials, principles of transmission and perception of load combinations.

In the most General case, the system (from the Greek "sistema" - "whole, composed of parts") refers to some commonality (integrity), organized on the basis of a certain principle, in which all the elements are so interdependent from one another, that act with respect to the environment and other systems, as a single and integral entity [13,14].

The consistency of the architectural environment is formed by the consistency of the human life, focused on the analysis of the surrounding world (space). The theory of systemic architectural environment (as part of the General theory of systems) extends the boundary of research in architecture - in an effort to display its unity in the form of a system of interrelated models that are suitable for use in their theoretical representations (in the form of provisions and principles of architectural science) and in practice (in the form of appropriate architectural systems).

Architectural practice involves the formation of artificial systems, which are usually understood as organized material structures and related functional processes of life and production activity, which allow to implement certain efforts to achieve this goal. The architectural systems intended for a certain type of utilitarian and functional activity acquire the status of architectural (production, town-planning) object and are systematized according to certain typological signs and classification rules.

The architectural system is a creative means that does not depict an object (as it is carried out, for example, objects of fine art: drawing, painting, sculpture - reproducing phenomena of reality), but creates an object (a product of architectural activity), which is determined by the functional and artistic meaning and purpose.

The architectural system can be understood as an artificially created integral architectural work, which is characterized by the following main features $[8,10,15,16]$ :

- own functional purpose;

- a set of individual (unique) or common (typical) features; 
- original aesthetic value and cultural level of display;

-the author's vision of adaptation and interaction with the natural (natural landscape) and artificial (architectural, urban) environment;

- way of interaction of internal spatial structure with external social and social.

The ratio of form and content is revealed in the composition of the architectural system (in the format of an architectural object), as a characteristic of the organization of the system interaction of the main elements and parts (subsystems and elements) and is determined by the unity of structure and function, due to the artistic content and aesthetic representation.

Compositional techniques, in which the synthesis of tectonic features and artistic expressiveness of the architectural system is used, are diverse in the formats of implementation and emotional impact.

The creation of architectural systems is based on the compositional solution of their spatial structure, which is formed in strict accordance with the rules and worldview of the relevant era, the level of development of the productive forces of society, as well as modern social and social conditions $[8,10,16,18,19]$.

Depending on the level of development of scientific knowledge, the state of technical and technological capabilities for manufacturing and practical implementation through appropriate construction techniques, architectural systems are classified into several main types (order, arch-vaulted, wall, frame-rack) [18].

Each of the main types of architectural systems is characterized by certain tectonic features, technical (technological) logic, capabilities and certain laws for architectural shaping.

Architectural practice of different (past) historical epochs establishes some regularity of tectonics, as a result of displaying the interaction of structural.

\section{Results and discussions}

As a result of the conducted research, the main types (groups) of influence factors were established, which determined the peculiarities in state and direction development, qualitative and quantitative indicators at the traditional tectonic (architectural) systems. In this article are presented the conceptual apparatus, which are in categories: "tectonics" and "system", as subject signs display of the features in voltage processes and the state at internal space the architectural images. The value of tectonics, as a specific means architectural expressiveness, which organically associated with the architectural (constructive) system and the objective laws in its creation, is shown. The nature interaction of the functional, constructive and artistic-aesthetic components in tectonic mapping at features architectural solutions in the formation the objects in spatial environment is established. Are considered the tectonic features of the presentation in main (traditional) types architectural systems (by the example of order systems), which are characterized by individual logic, expressiveness and regularities his architectural formation.

\section{Conclusions}

The studies have shown a complex and multifactorial composition of processes and phenomena that contributed to the formation and development of the features of the tectonic display of the main (traditional) architectural fact. The historical and geographical scale of the functioning and Genesis of these systems indicates the possibility of their subsequent application in architectural activity, taking into account the possible, promising 
(innovative) modifications of the structural, material, artistic and aesthetic components, as well as the harmonization of the integral spatial composition of the architectural image.

The ability and disposition to possible structural, functional and artistic transformations is a promising feature and potential area of application for the development of more technological methods of shaping (construction) and ways of organizing the internal space of architectural objects of various functional and technological purposes.

\section{References}

1. M. W. Maier, E. Rechtin, The Art of Systems Architecting, (2009)

2. M. Fazio, M. Moffett, L.Wodehouse, A World History of Architecture (2008)

3. Ye. A. Chernaya, Civ. Engin. Bull, 55-66, (2016)

4. M. N. Kokarevich, Tomsk St. Un. Architec. Civ. Engin. Bull. 64-74 (2015)

5. A. A. Andrianova, Article in the conference proceedings collection. Problems and prospects of development of Russia. Youth look into the future, 228-230

6. S. Psarra, F. Kostourou, K. Krenz, Plan J. 15-32 (2016)

7. M. M. Chervyakov, Tectonic image of an architectural object in the conditions of artificial illumination: dissertation for the degree of candidate of architecture (2012)

8. L. I. Taurashvili, Composition theory as the poetics of architecture (2012)

9. Yonca Hurol, The Tectonics of Structural Systems (2015)

10. M. A. Cohen, M. Delbeke, Proportional Systems in the History of Architecture: A Critical Reconsideration (2018)

11. E. Ganebnykh, T. Burtseva, A. Petuhova, A.Mottaeva, E3S Web of Conferences 91,08035, (2019) DOI: 10.1051/e3sconf /20199108035

12. M. Sepe, M. Pitt, Urban Design Intern. 215-227 (2014)

13. A. Mottaeva, , E3S Web of Conferences 110, 02166, (2019) DOI: 10.1051/e3sconf /201911002166

14. C. Malacrino, Constructing the Ancient World: Architectural Techniques of the Greeks and Romans, (2010)

15. Y. U. Yankovskaya, Image and morphology of an architectural object : dissertation for the degree of Doctor of Architecture (2006)

16. A. Mottaeva, A. Zheltenkov, E3S Web of Conferences 33, 01038 (2018) DOI: 10.1051/e3sconf/20183301038

17. V. G. Borkovskaya, E. Degaev, I. Burkova, MATEC Web of Conf. 193 (2018) DOI: $10.1051 /$ matecconf/201819305027.

18. V. Polyakova, E. Degaev., El Haddad P. MATEC Web of Conferences 251 (2018). DOI:10.1051/matecconf/201825106017

19. E. Degaev., A.Orlov, El Haddad P., A.. MATEC Web of Conferences 251 (2018), DOI: 10.1051/matecconf/201825106013

20. V. Alpatov, A. Lukin, I. Laguta, MATEC Web of Conferences 251, 04007

(2018). DOI: 10.1051/matecconf/201825104007 